\title{
IDENTIFICAÇÃO DE POTENCIAL DE SPILLOVERS DE ATIVIDADES SETORIAIS NA MESORREGIÃO SUL BAIANO
}

\author{
Lívio Andrade Wanderley \\ Doutor Administração (FGV/SP) \\ Professor do Programa de Pós Graduação em Economia da Universidade Federal da Bahia \\ (PPGE/UFBA). \\ Bahia, BA, Brasil. \\ Luiz Gustavo Casais e Silva \\ Mestrando em Economia do Programa de Pós-Graduação em Economia \\ Universidade Federal da Bahia (PPGE/UFBA). \\ Bahia, BA, Brasil. \\ Edilson Vasconcelos Júnior \\ Mestrando em Economia do Programa de Pós-Graduação em Economia. \\ Universidade Federal da Bahia (PPGE/UFBA). \\ Bahia, BA, Brasil.
}

\begin{abstract}
RESUMO - Este artigo discute a importância dos setores de referência - cacaueiro, celulose e do Polo de Informática de Ilhéus - sobre as atividades setoriais selecionadas da mesorregião Sul Baiano. A principal hipótese utilizada é de que esses setores de referência geram efeitos virtuosos de transbordamento, puxando o crescimento dos demais setores da economia. Para tanto, utilizou-se o Coeficiente de Associação Geográfica como ferramenta de mensuração, na tentativa de se estabelecer com mais precisão o grau de associação. Com base nesse estudo, concluiu-se que entre os setores de referência apenas o cultivo de cacau e o setor de informática registraram alta associação geográfica, além do fato do cacau, a celulose e o Pólo de Informática de Ilhéus possuem influências, mas com distintos pesos no que tange a proliferação sobre outras atividades econômicas.
\end{abstract}

Palavras-chave: Sul Baiano; Cacau; Celulose; Pólo de Informática; Coeficiente de Associação Geográfica.

\section{IDENTIFICATION OF SPILLOVERS 'POTENTIAL OF SECTORAL ACTIVITIES IN THE SOUTHERN BAHIA MESORREGIÃO}

\begin{abstract}
This article discusses the importance of the reference sectors - cocoa, pulp and Polo Ilheus Computer - on selected sectoral activities mesoregion South Baiano. The main hypothesis used is that these reference sectors generate virtuous spillover effects, pulling the growth of other sectors of the economy. For this, we used the Geographic Association coefficient as measurement tool in an attempt to establish more accurately the degree of association. Based on this study, it was concluded that among the reference sectors only cocoa farming and the computer industry were up geographic association, in addition to cocoa fact, the cellulose and the Ilheus Computer Pole have influences but with different weights with respect to proliferation of other economic activities.
\end{abstract}

Keywords: South Baiano; Cacau; Cellulose; Computer Pole; Geographic Association Coefficient.

\section{INTRODUÇÃO}

Com a chegada dos portugueses em Porto Seguro e a elevada demanda europeia por açúcar, os portugueses perceberam grande oportunidade de lucros e introduziram a cultura da 
cana-de-açúcar entre 1500 e 1550 nas Capitanias Hereditárias de Ilhéus e Porto Seguro. Apesar de seu pioneirismo, a cana-de-açúcar não vingou em decorrência dos contínuos ataques indígenas à região (NASCIMENTO et al., 2009). Entre os séculos XVI e XIX, a faixa costeira possuía população rarefeita, baseada em produção de subsistência e exportação, como criação de gado mandioca, milho, feijão, coco.

Em 1752 o cacau foi introduzido no município de Canavieiras, localizado na microrregião de Porto Seguro na Bahia. O cacaueiro se adaptou bem à região, quando, no século XIX se expandiu por toda a região sul da Bahia - hoje conhecida como mesorregião Sul Baiano -, tornando a Bahia o maior produtor de cacau do Brasil. Esta cultura agrícola foi a principal atividade da economia baiana, especialmente, na primeira metade do século XX. No que pese a continuidade da relevância do cacau, a economia baiana iniciou a sua diversificação com a implantação em 1950 no Recôncavo Baiano da Refinaria Landulpho Alves (RLAM). No final dos anos de 1960, implanta-se o projeto do Centro Industrial de Aratu (CIA), e nos anos de1970 e 1980 a implantação e implementação do Pólo Petroquímico de Camaçari. Na segunda metade da década de 1980, o cultivo do cacau foi acometido do fungo conhecido como "vassoura-debruxa" que apareceu no município de Camacã e rapidamente se espalhou pelas lavouras da região. Apesar disso, a Bahia permanece em seu posto de maior produtor, porém com sua produção, segundo dados de 2006, reduzida a menos da metade de seu auge.

Diante dos incentivos do Governo Federal na década de 1970 para o plantio de eucaliptos no país, o Extremo Sul da Bahia na década de 1980 iniciou a implantação das primeiras unidades de produção e empresas, atraídas pelas condições edafoclimáticas, preço da terra, escoamento da produção via portos de Vitória no Espírito Santo e de Ilhéus na Bahia, disponibilidade de mão de obra e grandes extensões de terras para a prática dos cultivos de eucalipto. De acordo com Guerra (1995 apud NASCIMENTO et al., 2009), o eucalipto é uma espécie de árvore mais plantada no Brasil, liderando a produção de celulose de eucalipto no mundo, com cerca de $50 \%$ da produção mundial à frente de países como Portugal e África do Sul. Representando 4\% do PIB brasileiro, essa atividade é de grande importância para o país e também para Bahia. A data de início da produção de celulose e pasta na Bahia foi em 1991, quando a empresa Veracruz Florestal Ltda. - subsidiária da Odebrecht - iniciou suas atividades na cidade de Eunápolis, localizada na microrregião de Porto Seguro (NETO, 2012).

Em 1995, 10 anos após o aparecimento da vassoura-de-bruxa nos cacaureiros da região, surgiu na cidade de Ilhéus uma atividade empresarial intensiva em tecnologia: a indústria de hardware, a qual mais tarde se tornou conhecida como Polo de Informática de Ilhéus (PII). Desde então, muitos incentivos fiscais foram oferecidos a fim de atrair novas empresas ao local, desencadeando uma guerra fiscal com os estados de São Paulo, Paraná, Minas Gerais e Rio de Janeiro. Recentemente, os 
efeitos dessa guerra têm afetado o PII: muitas empresas por não conseguirem ser competitivas encerraram suas atividades ou migraram para outro local que ofereça maior incentivo fiscal.

Como já defendia Furtado (1987 apud TSCHÁ et al., 2010), a capacidade de associação e de efeitos virtuosos entre determinadas atividades produtivas é um aspecto importante para determinado ramo industrial alcançar a competitividade, gerando crescimento $\mathrm{e}$ desenvolvimento econômico. Sendo assim, fazem-se três questionamentos:

1) As três atividades de referência - cacau, celulose e informática - têm fortes associação geográfica entre si que potencializam a proliferação em outras atividades econômicas na mesorregião Sul Baiano?

2) A associação geográfica das atividades cacaueira, celulose e do polo de informática de Ilhéus na mesorregião Sul Baiano é capaz de gerar spillovers para outros setores tal que estimulem o dinamismo econômico regional?

3) Os potenciais de spillovers entre as atividades de referência - cacau, celulose e informática - são significativamente distintos em suas influências sobre outros setores?

Desse modo, este estudo tem como objetivo analisar a associação geográfica dos ramos de atividades Cacaueira, Celulose e do Polo de Informática de Ilhéus entre si e com os demais ramos de atividades nas microrregiões de Valença, Ilhéus-Itabuna e Porto Seguro do estado da Bahia, com base no Coeficiente de Associação Geográfica. O estudo dessa amplitude espacial se justifica por razões naturais, ou seja, é na mesorregião Sul Baiano que está instalado o Polo de Informática de Ilhéus e onde as áreas são aptas tanto ao cultivo de cacau quanto à silvicultura do eucalipto no Estado.

Além desta introdução são apresentados na seção 2 os aspectos conceituais. Na seção 3,faz-se uma contextualização econômica e caracterização do espaço em questão. Na seção 4, é apresentada a técnica de medida do Coeficiente de Associação Geográfica. Na seção 5, apresentam-se as análises dos resultados dos indicadores intersetorial. Na seção 6, têm-se as conclusões do artigo.

\section{UM ESBOÇO CONCEITAL}

Para verificação dos objetos selecionados, é importante expor brevemente os conceitos de encadeamento, redes e cluster $^{l}$, uma vez que se quer entender como uma atividade econômica é capaz de transbordar e afetar positivamente outros setores, inclusive, aqueles distantes da região em questão, de modo a também modificar aspectos urbanos e sociais.

\footnotetext{
${ }^{1}$ É importante ressaltar que há outros vetores importantes do desenvolvimento regional. Pode-se citar, por exemplo, os Arranjos Produtivos Locais. Muito menos não se tem a pretensão de afirmar que os três conceitos expostos são os mais importantes. \begin{tabular}{llllll}
\hline REVISTA ECONOMIA POLÍTICA DO DESENVOLVIMENTO & Maceió - AL & V.2 N.4. & DEZEMBRO/2015 & P.54-75 & Página-56
\end{tabular}
} 
Sobre o conceito de encadeamentos, Syrquin (1992) coloca que "points out that, although similar ideas can be found in authors such as Rostow, Gerschenkron, and Perroux, Hirschman was the sole economist to bring over the idea of linkages as a feature to guide a deliberate strategy of development ${ }^{\text {"2 }}$. Ainda sobre a idéia de linkages, temos:

Os encadeamentos, segundo o autor, sugerem interdependência e esse termo pode ser
usado para assinalar inter-relações em um sistema estável, em que tudo depende de
tudo, e também para dar significado a uma variedade de efeitos multiplicadores, até
mesmo de transbordamento. Esse conceito adquiriu sentido mais característico e real
ao ser usado para indicar mecanismos de indução em ação no setor de atividades
inteiramente produtivas, mostrando-se menos ambíguo do que os conceitos
alternativos.(TSCHÁ et al., 2010, p. 130).

De acordo com Hirschman (1985), a principal fonte de desenvolvimento seriam as atividades com alto potencial de gerar encadeamentos, principalmente encadeamentos para trás. Encadeamento para trás estimulam setores que fornecem insumos demandados por uma atividade qualquer, enquanto encadeamentos para frente levam ao estabelecimento de novas atividades que utilizam o produto da atividade sugerida (TSCHÁ et al., 2010).

Sendo assim, é importante observar que setores de alto potencial de encadeamento geram um efeito mútuo entre os efeitos de aglomeração, de forma que quando esses setores indutores atuam conjuntamente num espaço geram muito mais encadeamentos do que quando atuam isoladamente (SHIKIDA e STADUTO, 2005apud TSCHÁ et al., 2010).

Sobre o conceito de redes, segundo Toledo Junior (2003, p. 93 apud NETO, 2012, p.8): “as redes podem ser entendidas tanto como a presença de uma infraestrutura no território quanto pelos serviços que esta permite que se realizem". Isto é, a construção de nova infraestrutura com intuito de viabilizar o funcionamento de uma fábrica gera efeitos virtuosos tais que tendem a se propagar à população. Essa nova infraestrutura, independente de ser construída pelo governo ou pela companhia, podem diretamente criar externalidades positivas sobre o bem-estar da população em forma de aumento nos postos de trabalho e crescimento na renda da região, e externalidades indiretas pelo usufruto dessa infraestrutura pela população. Se, por exemplo, a construção de uma estrada asfaltada fizer parte da infraestrutura criada, a população local poderá se locomover com mais facilidade, por exemplo, e na beira da estrada poderão construir estabelecimentos comerciais com intuito de atender motoristas que por ali trafegam.

O termo cluster é utilizado em diversas áreas da ciência com o sentido de agrupamento. Este termo foi popularizado por Michael Porter em seu livro, de 1989, A vantagem competitiva

\footnotetext{
2 “Ressalta que, apesar de que idéias semelhantes podem ser encontradas em autores como Walt. W. Rostow, Alexander Gerschenkron e François Perroux; Albert Hirschman foi o pioneiro na ênfase dada aos linkages como elemento primordial de uma estratégia de desenvolvimento econômico" (BIANCHI, 2007).
} 
das nações. Ele enfatiza a importância dos vínculos e fluxos de conhecimentos que emergem das relações entre agentes locais na conquista de vantagens competitivas. Segundo Porter (1998)

\begin{abstract}
Clusters são concentrações geográficas de empresas inter-relacionadas, fornecedores especializados, prestadores de serviços, empresas em setores correlatos e outras instituições específicas (universidades, órgãos de normatizações, entidades comerciais e de classe, governo, entre outras), vinculadas por elementos comuns e complementares, que competem e cooperam entre si. (SANT'ANNA, 2009, p. 727).
\end{abstract}

Segundo Casarotto Filho e Pires (2001 apud SANT'ANNA, 2009), o cluster desenvolvese sob a vocação regional, podendo conter empresas produtoras de bens finais - verticalizar-se a jusante (serviços) - ou fornecedoras de insumos - a montante (fornecedores) -, além de incluir associações de suporte privadas ou ligadas ao governo. Porém, não significa que um cluster necessariamente contenha toda uma cadeia produtiva, pois pode ainda conter apenas relações de parcerias informais, ou seja, comerciais ou negociais.

\footnotetext{
Os clusters influenciam a competição de três maneiras: primeiro pelo aumento da produtividade das empresas, segundo, pela elevação da capacidade inovativa e, por último, pelo estímulo ao surgimento de novas empresas, que levam ao crescimento do cluster. Muitas de suas vantagens são decorrentes de economia externas às empresas ou de outros efeitos advindos do setor. Assim sendo, os clusters podem ser definidos como um sistema de empresas e instituições inter-relacionadas, cujo valor como um todo é maior que a soma das partes. (SANT'ANNA, 2009, p. 727).
}

Dois elementos importantes na formação dos clusters são a induções da demanda e da oferta e as implicações dos encadeamentos - já tratados anteriormente -, enfatizando a necessidade de desenvolver setores que mantenham vínculos com muitos outros.

Competição moderna depende muito mais da produtividade do que no acesso a insumos. Segundo Porter (1998), os clusters são ambientes adequados na promoção não apenas da produtividade, mas no aumento do ritmo de inovações - as quais desencadearão novos aumentos de produtividade - e no estímulo da formação de novos negócios, os quais expandem e fortalecem o cluster em si. A experiência histórica mostra que, em diversas circunstâncias, o cluster é uma boa alternativa devido a alguns fatores: (i) o cluster cria um ambiente propício à subcontratação, a qual reduz os custos de transação; (ii) a subcontratação dissolve os riscos de flutuações do mercado; (iii) a subcontratação estimula novas inovações em virtude da maior especialização (BENKO, 1999).

\title{
CONTEXTO ECONÔMICO
}

A região Sul da Bahia, definida pelo IBGE como Mesorregião do Sul Baiano, Figura 1, compreende um conjunto de 70 municípios que abrangem uma área territorial de aproximadamente $54.642,351 \mathrm{~km}^{2}$. A contagem populacional realizada pelo IBGE em 2007 informa um contingente de 2.006 .832 habitantes, estando subdividida em 
microrregiões de Ilhéus-Itabuna com 1.081.347 habitantes, de Porto Seguro com 678.536 habitantes e de Valença com 266.566 habitantes.

FIGURA 1: Estado da Bahia e Mesorregião do Sul Baiano

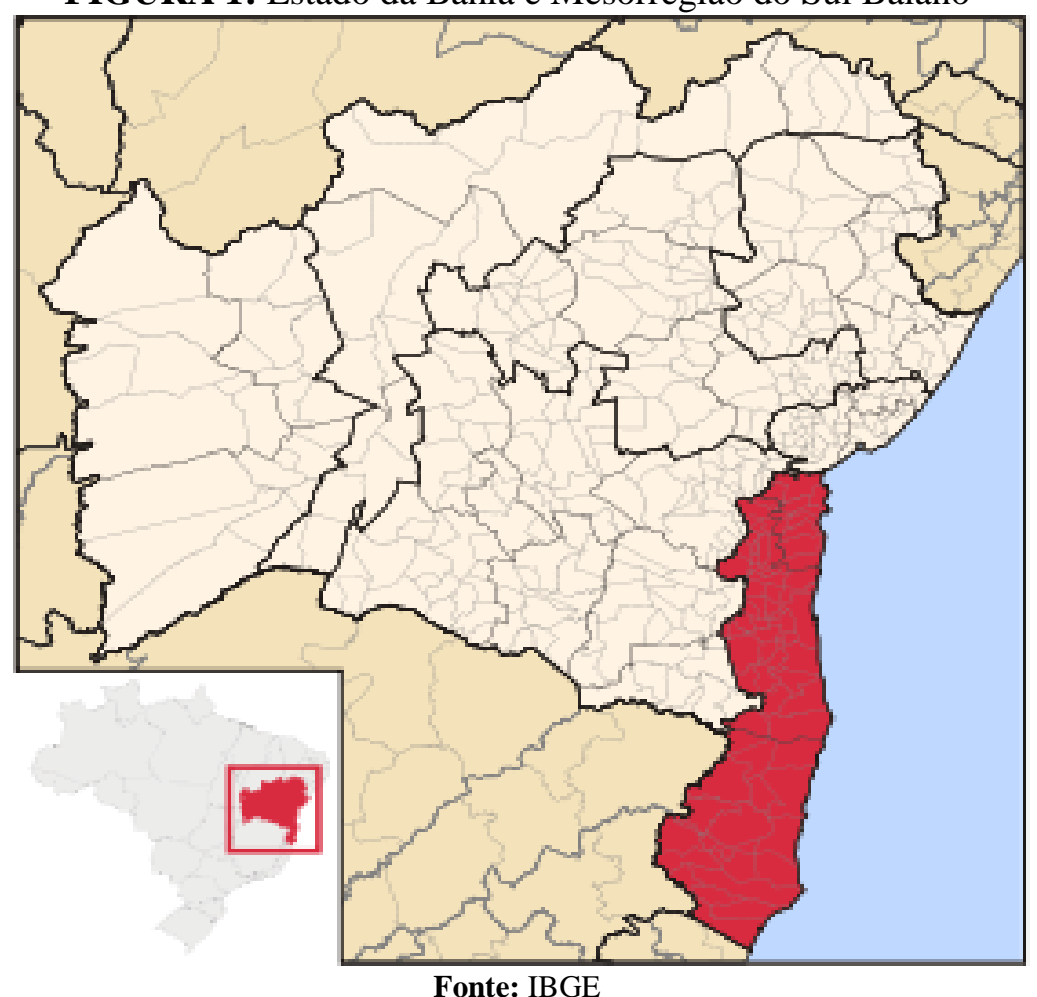

A mesorregião Sul Baiano é conhecida por ser historicamente uma área de grande produção de cacau. Mais recentemente, além do cacau, a produção de celulose e o polo de informática de Ilhéus se tornaram importantes atividades na economia da região.

O cacaueiro encontra local de cultivo propício num ambiente de clima úmido, chuvas bem distribuídas ao longo do ano, temperaturas médias ao redor de $24^{\circ} \mathrm{C}$, solo profundo, poroso e fresco. Não por menos, o litoral da mesorregião Sul Baiano adquiriu o posto de maior produtor de cacau do Brasil, cujo cultivo se iniciou em 1752 no município de Canavieiras. O Brasil se tornou o $5^{\circ}$ maior produtor do mundo, caracterizado por sua produção essencialmente para exportação e polo gerador de emprego. No princípio, as lavouras se restringiam às cidades de Canavieiras, Belmonte, no sentido sul, e a Ilhéus e Itabuna sentido norte. No século XIX, houve grande expansão da área de cultivo, migrando ao extremo sul da Bahia, à cidade de Mucuri, e, ao norte, a Valença. Mapas mais recentes mostram que o cacau está presente em cidades mais distantes do litoral como é o caso de Caatiba e Jequié, e também ao norte, a despeito da pequena área de plantio, nas cidades de Amargosa e Nazaré; seguindo mais para o norte, encontram-se lavouras de cacau no Recôncavo Baiano e na região metropolitana de Salvador (NASCIMENTO et al., 2009). 
Até meados do século $\mathrm{XX}$, havia grande expectativa de prosperidade na região Sul, oferta de emprego e possibilidade em aquisição de terras próprias para o próprio cultivo de cacaueiros. Contudo, economistas criticam, com razão, uma economia baseado na monocultura, visto que, em tempos de crise econômica, uma das primeiras consequências é a queda nos preços das commodities. Sendo assim, o efeito da crise de 1929 sobre os produtores de cacau foi enorme, houve grande prejuízo de maneira que o Governo da Bahia criou o Instituto do Cacau em 1931. A despeito da crise, empreendimentos regionais como a construção da linha ferroviária entre 1931 e 1934 - que interligava centros produtores nas cidades de Ilhéus, Itabuna, Uruçuca e Itajuípe -, a construção de uma rodovia e o porto fluvial do Jequitinhonha em 1941, fizeram com que o período subsequente, poucos anos após a crise de 1929, fosse marcado pelo grande crescimento da produção cacaueira. A segunda crise se abateu em 1957 e 1964/65, devido à expansão da lavoura de cacau pelas colônias europeias na África subsaariana - como resultado, foi criada a Comissão Executiva do Plano da Lavoura Cacaueira (CEPLAC) (NASCIMENTO et al., 2009).

De acordo com o Quadro 1, entre 1940 e 2006, o auge da produção de cacau no extremo Sul da Bahia foi em 1985. Nesse ano, o fungo conhecido popularmente como "vassoura-de-bruxa" apareceu no município de Camacã, espalhando-se depois para Canavieiras, Belmonte e por quase toda região, causando destruição e prejuízo aos produtores de cacau. Por causa dessa praga, o preço da tonelada de cacau negociado na bolsa de valores de Nova Iorque caiu significativamente. Durante este período muitas fazendas foram abandonas, e os trabalhadores tiveram de migrar para centros urbanos em busca de emprego. Recentemente, a técnica de melhoramento genético e a clonagem do fruto geneticamente modificado - resistente à "vassoura-de-bruxa" - obtiveram bons resultados no combate à praga, evidenciados pelo crescimento da produção.

QUADRO 1: Produção de Cacau nos Municípios de Belmonte e Canavieiras na Bahia entre 1940 e 2006

\begin{tabular}{|c|c|c|c|c|c|c|c|c|c|c|}
\hline \multirow{2}{*}{ Municípios } & \multicolumn{10}{|c|}{ Quantidade Produzida } \\
\cline { 2 - 13 } & 1940 & 1950 & 1960 & 1970 & 1980 & 1985 & $1995 / 96$ & 1999 & 2000 & 2006 \\
\hline Belmonte & 7.008 & 7.079 & 5.966 & 4.834 & 5.332 & 6.379 & 5.819 & 1.742 & 2.060 & 3.291 \\
\hline Canavieiras & 8.555 & 13.159 & 14.874 & 6.040 & 10.682 & 12.935 & 4.040 & 1.284 & 864 & 1.100 \\
\hline BAHIA & 103.269 & 139.431 & 161.581 & 195.027 & 328.608 & 381.034 & 204.168 & 159.328 & 137.568 & 148.703 \\
\hline
\end{tabular}

Fonte: IBGE (2006, 2008a) apud NASCIMENTO et al. (2009).

A produção de celulose na Bahia se iniciou em 1991, na cidade de Eunápolis, situada na microrregião de Porto Seguro a partir do início do funcionamento da empresa Veracruz Florestal Ltda., subsidiária da Odebrecht (NETO, 2012). O plantio de eucalipto nessa região não se iniciou apenas por fatores ambientais - isto porque as condições climáticas de temperatura, a distribuição das chuvas e o solo são bastante propícios para o crescimento do \begin{tabular}{llllll}
\hline REVISTA ECONOMIA POLÍTICA DO DESENVOLVIMENTO & Maceió - AL & V.2 N.4. & DEZEMBRO/2015 & P.54-75 & Página-60
\end{tabular} 
eucalipto -, mas também decorrente de estímulos do Estado pelo II Plano Nacional de Desenvolvimento (1975-1979), cujo intuito foi superar os desequilíbrios setoriais a fim de garantir o crescimento econômico brasileiro (NETO, 2012). Contudo, vale salientar que a cultura madeireira se remete à década de 1950, impulsionado pelo recém-criado Banco do Nordeste, quando houve desmatamento generalizado da Mata Atlântico a fim de expandir a área de criação de gado, contudo após a inauguração de trecho da BR-101 - a região atraiu muitas empresas madeireiras em virtude da abundância de madeiras nobres e dos incentivos fiscais. Segundo Silva e Mendonça (2005 apud SANT'ANNA, 2009),

\begin{abstract}
A prática destrutiva do desmatamento predatório seguido da queimada torna-se rotineira. Junto ao empobrecimento genético, representado pelo desaparecimento de centenas de espécies nativas da região, e à degradação do solo, instala-se a pecuária extensiva e com ela a falta de cuidado com as pastagens. É esse ambiente de predomínio de pastagens degradadas que irá receber o eucalipto (Sant'Anna, 2009, p. 728).
\end{abstract}

O eucalipto possui vantagem sobre outras espécies: ele se adapta muito bem a solos pouco férteis, de modo que a degradação do solo, no Extremo Sul da Bahia, não foi impedimento para silvicultura e produção de celulose. É importante ressaltar que a cultura do eucalipto no extremo sul da Bahia segue ocupando áreas já desmatadas, principalmente pastagens degradadas, provocando melhorias ambientais em relação ao uso anterior, visíveis em um curto espaço de tempo. O ambiente oferecido pela região é bastante vantajoso, onde o corte do eucalipto se dá entre seis e sete anos após o plantio. Comparando-se com a Suécia, onde eucalipto demora entre 20 a 40 anos para atingir o tamanho adequado e ser cortada, a vantagem da região baiana é fica evidente (CARNEIRO, 1994 apud NASCIMENTO et al., 2009).

Os efeitos da produção de celulose na microrregião de Porto Seguro foram consideráveis, a começar pelo aumento da população. Na cidade de Porto Seguro e municípios como Mucuri e Eunápolis o crescimento da população não foi o único efeito derivado do plantio de eucalipto e produção de celulose, estima-se, por exemplo, que em Mucuri 13 mil empregos foram criados no em torno, entre os quais gerados pelo aparecimento de consultórios, clínicas, fabricação de móveis, reformas de hotéis etc.. Anteriormente, Porto Seguro dependia essencialmente do turismo, cuja renda gerada é sazonal. Hoje, a renda advinda do eucalipto, além de amenizar essa sazonalidade, foi fator crucial na modificação da dinâmica econômica da cidade ${ }^{3}$. Exemplos de povoados e municípios que se beneficiaram com a instalação de fábricas de celulose no extremo Sul da Bahia são muitos - e que por isso não é necessário citar cada um deles.

Quando se observa os exemplos citados de cidades que cresceram em seus mais diversos aspectos, derivadas da dinâmica econômica do cacau, da celulose ou do polo de informática de

\footnotetext{
${ }^{3}$ Conforme NETO (2012), parte da população dessas cidades criticam essa guinada econômico em virtude do aumento do preço dos imóveis.

\begin{tabular}{llllll}
\hline REVISTA ECONOMIA POLÍTICA DO DESENVOLVIMENTO & Maceió - AL & V.2 N.4. & DEZEMBRO/2015 & P.54-75 & Página-61
\end{tabular}
}


Ilhéus, encontram-se efeitos gerados por essas atividades sobre o espaço. Como exemplo, temos a geração de infraestrutura de acordo com a necessidade da atividade econômica. Estima-se que somente a Veracel tenha construído $110 \mathrm{~km}$ de estradas asfaltadas e $1.500 \mathrm{~km}$ de estradas de cascalho na região de Eunápolis. Tomando este exemplo retirado de NETO (2009), podemos inferir que os moradores da região se beneficiaram por essas estradas por diversas razões, entre as quais criação de restaurantes de beira de estrada, facilidade do transporte, crescimento da urbanização, do comércio etc. (NETO, 2009; NASCIMENTO et al., 2012).

Certamente as redes possuem papel importante nos efeitos do cacau, celulose e da informática sobre a localidade da atividade realizada e o em torno, mas que além deste há os fenômenos conhecidos como encadeamentos e clusters.

Na região analisada, o cluster madeireiro do extremo sul da Bahia é uma parte de um cluster maior - este compreendendo quatro grandes empresas: duas na Bahia, uma no Espírito Santo e outra em Minas Gerais. O importante ponto de relacionamento entre elas é o terminal de Protocel, localizado na cidade de Aracruz - ES, é o único porto do Brasil especializado no embarque de celulose através do qual a maior parte da celulose é exportada. Devido ao fato de a celulose ser um produto de baixo valor agregado, é importante que o seu transporte seja feito em grande quantidade de modo a diluir os custos. Nesse sentido, além dessa importante aquisição, o cluster madeireiro engloba também o financiamento estatal do BNDES. De acordo com Sant'anna (2009, p. 738), este

Binômio provisão de recursos-acúmulo de conhecimento permitiu desenvolver uma indústria internacionalmente competitiva, sob controle nacional, e formar uma base de tecnologia florestal extremamente avançada, capaz de garantir aumentos constantes de produtividade.

No âmbito local, o cluster madeireiro no extremo sul da Bahia é inter-relacionado com diversas associações de empresas que prestam serviço às empresas de celulose e papel como a Associação das Empresas Prestadoras de Serviços do Extremo Sul da Bahia e Associação Baiana de Produtores de Florestas Plantadas. Por ser o quinto maior produtor do Brasil, a área de influência na Bahia do cluster madeireiro é considerável: gera US\$ 800 milhões por ano, 25 mil empregos diretos e 100 mil indiretos - além de estar comprometido na preservação de áreas de Mata Atlântica e fomentar Arranjos Produtivos Locais de madeiras e móveis e de apicultura (SANT'ANNA, 2009).

Em meados da década de 1990, uma nova atividade da cidade Ilhéus foi implantada e consolidada, depois que uma grande empresa de equipamentos de informática migrou do Espírito Santo. O que foi uma promessa de um novo Vale do Silício em solo baiano, contudo, não permaneceu mais do que três anos no auge, entre 2004 e 2007. 
O Polo de Informática de Ilhéus (PII), quando surgiu, foi esperança de desenvolver, na Bahia, um local atraente para grandes empresas de tecnologia de ponta. Contudo, as empresas que se localizam no PII sempre produziram essencialmente componentes de computadores placas-mãe, monitores, teclados etc. -, bens eletro-eletrônicos e equipamentos de telecomunicação. Segundo Ferreira Júnior et al. (2006), os perfis dessas empresas pouco colaboram para consolidação de um encadeamento; o pequeno volume de comércio do PII com o mercado local, incluindo-se o próprio polo, revela isso. Dois são os fatores que podem explicar essa orientação estratégica empresarial: (i) reduzido tamanho do mercado regional e (ii) o fato de muitas serem empresas que já eram atuantes no mercado nacional. Agora, quando essas duas explicações são confrontadas com os principais motivos que levaram essas empresas a se instalarem em Ilhéus - de acordo com a pesquisa de Ferreira Júnior et al. (2006) -, a saber, incentivos fiscais e mão-de-obra relativamente barata, nota-se que o PII é constituído fundamentalmente por empresas que vieram em busca de mão-de-obra barata e pouco qualificada, o que corrobora com a explicação acima. O prognóstico dado a respeito foi esse:

O PII tem sua competitividade baseada em incentivos fiscais, e não em fatores sistêmicos, sendo, portanto, de difícil sustentação no longo prazo. As empresas incentivadas geralmente não se preocupam, para serem competitivas, em criar localmente efeitos de encadeamento a montante e a jusante da cadeia. Consequentemente, essa ausência de encadeamento leva a que, ao terminarem os incentivos, as empresas deixem o local em que estão implantadas e migrem em direção a locais que ofereçam incentivos similares (FERREIRA JÚNIOR et al., 2006, p. 431).

Assim que as guerras fiscais interestatal começaram, o movimento migratório empresarial explicitou o objetivo das empresas. Recentemente, cerca de 20 empresas no PII fecharam as portas e/ou retornaram a suas regiões de origem, a fim de obter acesso a melhores vantagens competitivas. Por isso, o governo do estado da Bahia tem oferecido linhas de crédito espacial, com intuito de refrear esse movimento pernicioso contra o PII.

\section{INDICADOR DE ASSOCIAÇÃO GEOGRÁFICA E SETORIAL}

A teoria econômica regional fornece ferramentas de análises teóricas e empíricas que servem para orientar o raciocínio durante a investigação de um objeto de estudo. Apesar das análises teóricas entre variáveis relevantes dos modelos econométricos, enfatiza-se que a análise empírica ancorada em determinas técnicas de aferição também tem a sua importância por ser sustentada através de testes de modelos alternativos existentes no plano teórico, como também por explorar maior riqueza de detalhes analíticos existentes nos modelos empíricos. Em HADDAD (1977) e HADDAD (1989 apud FONSECA, 2002) são apresentadas às medidas de localização e especialização, que auxiliam na formulação de políticas de descentralização industrial ou servem para o conhecimento dos padrões 
regionais de crescimento econômico. Algumas destas medidas são de natureza eminentemente descritiva e de escopo analítico bastante limitado, mas sua utilização justifica-se em trabalhos de natureza exploratória e em conjunto com outras técnicas.

O uso das técnicas de mensuração de localização setorial remete à construção da chamada "Matriz de Informações". A organização das informações em uma matriz configura uma amplitude espacial relacionando a distribuição setorial-regional de uma variável base. Com a matriz construída, o cálculo de diferentes tipos de medidas permitirá "descrever padrões de comportamento dos setores produtivos no espaço econômico, assim como padrões diferentes de estruturas produtivas entre as várias regiões." (HADDAD 1989, p. 227 apud FONSECA, 2002). As medidas de localização são de natureza setorial e se preocupam com a localização das atividades entre as regiões no âmbito de uma amplitude espacial, buscando identificar padrões de concentração ou dispersão espacial, de aglomeração ou desaglomeração setorial, de associação geográfica intersetorial, e de movimentos locacionais de setores, que correspondem aos respectivos indicadores denominados: Coeficiente de Localização, Quociente Locacional, Coeficiente de Associação Geográfica e Coeficiente de Redistribuição.

Este estudo visa fazer uma análise do Coeficiente de Associação Geográfica (CA) com a utilização da variável base "Emprego Formal" da base de dados do CNAE/RAIS/MTE. ${ }^{4}$ A construção da "Matriz de Informações" se refere a amplitude espacial da Mesorregião Sul Baiano, constituindo-se nas linhas com uma amostra de 25 setores de atividades segundo as Classes/CNAE e as 3 microrregiões do espaço em análise. A leitura dessa matriz envolve as amplitudes espacial, local, regional, e setorial que corresponde, respectivamente, ao conjunto de todos os setores e microrregiões ( $L t t)$, de cada setor e microrregião ( $L i j)$, do conjunto de todas as microrregiões por setores ( $L i t)$, e do conjunto de todos os setores por microrregiões $(L t j)$. A "Matriz de Informações" na qual a soma das linhas representa o total em cada microrregião e a soma das colunas representa o total de cada setor de atividade na Mesorregião do Sul Baiano, é apresentada a seguir através da Figura 2.

FIGURA 2:Modelo de Matriz de Informações da Mesorregião do Sul Baiano

\begin{tabular}{|c|c|c|}
\hline Setores de atividade & Microrregiões (j) & $\Sigma j=t$ \\
\hline (i) & Lij & $\Sigma L i t$ \\
\hline $\bar{a}=t$ & $\Sigma L t j$ & $\Sigma L t t$ \\
\hline
\end{tabular}

Sendo:

$$
\begin{gathered}
L i t=\sum i \sum j L i j \\
L t j=\sum j \sum i L i j \\
L t t=\sum i \sum j L i j=\sum j \sum i L i j .
\end{gathered}
$$

\footnotetext{
${ }^{4}$ Classificação Nacional Agregada de Atividades Econômicas/Relação Anual de Informações Sociais/ Ministério do Trabalho e Emprego.

\begin{tabular}{llllll}
\hline REVISTA ECONOMIA POLÍTICA DO DESENVOLVIMENTO & Maceió - AL & V.2 N.4. & DEZEMBRO/2015 & P.54-75 & Página-64
\end{tabular}
}


Sendo: L, o emprego formal; Lij, o emprego de cada setor de atividade i em cada microrregião de do Sul Baiano j (amplitude local); Lit, o emprego de cada setor de atividade $\mathrm{i}$ em todas as microrregiões do Sul Baiano $\mathrm{j}$ (amplitude regional); Ltj, o emprego em todos os setores de atividades de cada microrregião do Sul Baiano j (amplitude setorial); Ltt, o emprego em todos os setores de atividades de todas as microrregiões do Sul Baiano (amplitude espacial); i, são os setores de atividades ( $i=1, \ldots$, n); j, são as microrregiões do Sul Baiano $(\mathrm{j}=1, \ldots, \mathrm{m})$; n, é o número de setores de atividade e m, é o número de microrregiões do sul Baiano; t, são os somatórios dos setores de atividades ou das microrregiões.

A formulação do Coeficiente de Associação Geográfica (CAik) de cada atividade setorial identifica os graus de concentração ou dispersão geográfica em relação a um setor de atividade k , em um dado ano. Com base na estrutura da "Matriz de Informações", fazendo-se uso das relações entre as amplitudes local Lij e regional Lit e da referência de uma determinada atividade setorial k, obtém-se a técnica de medida do CAik:

$$
\begin{gathered}
\mathrm{CA}_{\mathrm{ik}}=\left\{\left[\sum \mathbf{j}\left(\left|\left(\mathrm{Lij}^{\mathrm{i}} / \mathbf{L i t}^{\mathrm{i}}\right) * 100-\left(\mathbf{L i j}^{\mathrm{k}} / \mathbf{L i t}^{\mathrm{k}}\right) * 100\right|\right)\right] / 2\right\} / 100 \\
0 \leq \mathrm{CA}_{\mathrm{ik}} \leq 1
\end{gathered}
$$

$\mathrm{k}=$ setores de atividades de referência: "Cultivo de cacau"; "Fabricação de celulose e outras pastas para a fabricação de papel”; "Fabricação de equipamentos de informática e Fabricação de periféricos para equipamentos de informática".

Sendo : $\mathbf{C A}_{\mathrm{ik}} \approx$ 1: a atividade i apresenta alto grau de dispersão em relação a atividade $\mathrm{k}$, pois os fatores locacionais das duas atividades são bastante diversos, inexistindo ou sendo insignificante a associação geográfica. É um indicativo da impossibilidade de k ser uma atividade pólo, da existência de cadeias produtivas (linkages) e/ou arranjos produtivos da atividade $\mathrm{i}$ em relação com a atividade $\mathrm{k}$.

$\mathbf{C A}_{\mathbf{i k}} \approx$ 0: a atividade i apresenta baixo grau de dispersão em relação a atividade $\mathrm{k}$, pois os fatores locacionais das duas atividades são bastante semelhantes ou iguais, existindo a associação geográfica significativa. É um indicativo da possibilidade de $\mathrm{k}$ ser uma atividade pólo, da existência de cadeias produtivas (linkages) e/ou arranjos produtivos da atividade i em relação com a atividade $\mathrm{k}^{5}$

Cabe ressaltar que a variável emprego apresenta suas limitações assim como qualquer outra selecionada para a base dos cálculos. A principal limitação se refere aos diferenciais

\footnotetext{
${ }^{5}$ Os resultados dos coeficientes de Associação Geográfica é um indicador exploratório, exigindo-se para a sua comprovação a realização de pesquisa qualitativa in loco.

\begin{tabular}{llllll}
\hline REVISTA ECONOMIA POLÍTICA DO DESENVOLVIMENTO & Maceió - AL & V.2 N.4. & DEZEMBRO/2015 & P.54-75 & Página-65
\end{tabular}
}


inter-regionais de tecnologia e de produtividade, pois pode ocorrer que duas regiões apresentem, para um mesmo setor produtivo, níveis de emprego semelhantes, porém, com volumes diferentes de produção em termos físicos ou monetários; ou então, com a evolução da tecnologia e da produtividade em um dado setor de uma determinada Região, ao longo do tempo, o decréscimo do nível de emprego entre dois períodos pode ser compatível com o crescimento da produção setorial (HADDAD, 1989 apud TSCHÁ etal., 2010).

\section{ANÁLISE DOS RESULTADOS}

Este estudo visa verificar se há interfaces das atividades setoriais de referência - "Cultivo de cacau", "Fabricação de celulose e outras pastas para a fabricação de papel", e "Fabricação de equipamentos de informática e fabricação de periféricos para equipamentos de informática" com os demais setores de atividades da mesorregião do Sul Baiano composta pelas microrregiões de Valença, Ilhéus-Itabuna e Porto Seguro. O instrumento de análise envolve os cálculos dos Coeficientes de Associação Geográfica (CAik) dos setores de atividades em relação a cada um dos setores de referências no ano de 2013.

Dado que quando $\mathrm{CA}_{\mathrm{ik}} \approx 0$, sinaliza-se uma forte associação geográfica das atividades setoriais i como o setor referência $\mathrm{k}$, o que vem a ser um indicativo em que $\mathrm{k}$ possa ser uma atividade pólo, da possibilidade de existir cadeias produtivas (linkages) e a de outros modelos de configuração produtiva, a exemplo, redes e cluster e arranjos produtivos. Neste sentido, pode-se aferir se as atividades setoriais de referência têm potencial de gerar efeito transbordamento (spillovers) das atividades de cultivo de cacau, de papel e celulose e de equipamentos de informática e periféricos, em seus correspondentes setores correlatos.

O fenômeno de transbordamento, no qual um setor passa a influenciar outro - seja por clustering, redes, encadeamento ou por ser pólo -, é analisado através do Quadro 2 que apresenta os indicadores de associação geográfica e setorial de vários setores com os correspondentes setores de referências acompanhados por um rank que ordena os setores de maior para os de menores sinergias. Observa-se que cada um dos setores de referência exerce influência em todos os setores da amostra selecionada, seja com Coeficientes de Associação Geográfica maior ou menor que 0,50. Enfatiza-se que são considerados na análise de identificação de potencial despillovers apenas os setores de Coeficientes de Associação Geográfica abaixo de 0,50 que registram maiores intensidades de proxi midade entre o setor referência e das demais atividades. 
QUADRO 2: Indicadores de Associação Geográfica e Setorial no Ano de 2013

\begin{tabular}{|c|c|c|c|c|c|c|}
\hline \multirow[b]{2}{*}{ Setores de atividades } & \multicolumn{6}{|c|}{ Setores de Atividades de Referência } \\
\hline & $\begin{array}{l}\text { 03.Cac } \\
\text { au }\end{array}$ & Rank & $\begin{array}{l}\text { 11. Fab.: } \\
\text { celulose etc }\end{array}$ & Rank & $\begin{array}{lr}12 . & \text { Fab. } \\
\text { de } & \text { eq. } \\
\text { infor. } & \end{array}$ & Rank \\
\hline 01. Frutas... & 0,72 & & 0,24 & $5^{0}$ & 0,83 & \\
\hline 02. Café & 0,85 & & $\mathbf{0 , 1 1}$ & $3^{\mathbf{0}}$ & 0,89 & \\
\hline 03. Cacau & 0,00 & & 0,96 & & $\mathbf{0 , 1 5}$ & $2^{-}$ \\
\hline 04. Plantas perm... & 0,68 & & 0,82 & & 0,83 & \\
\hline 05. Bovinos & 0,65 & & $\mathbf{0 , 3 1}$ & $6^{0}$ & 0,70 & \\
\hline 06. Ap.: agricultura & 0,79 & & $\mathbf{0 , 1 7}$ & $4^{0}$ & 0,90 & \\
\hline 07. Produção florestal & 0,95 & & $\mathbf{0 , 0 1}$ & $2^{0}$ & 0,99 & \\
\hline 08. Ap.: prod. florestal & 0,96 & & $\mathbf{0 , 0 0}$ & $\mathbf{1}^{\underline{0}}$ & 1,00 & \\
\hline 09. Fab.: laticínios & 0,52 & & $\mathbf{0 , 4 4}$ & $7^{0}$ & 0,56 & \\
\hline 10. Fab. der.: cacau... & $\mathbf{0 , 1 3}$ & $1^{0}$ & 0,98 & & $\mathbf{0 , 0 2}$ & $1^{0}$ \\
\hline 11. Fab.: celulose etc. & 0,96 & & $\mathbf{0 , 0 0}$ & & 1,00 & \\
\hline 12. Fab. de eq. infor. & 0,15 & $2^{\underline{0}}$ & 1,00 & & $\mathbf{0 , 0 0}$ & \\
\hline 13. Varej.:supermerc. & 0,45 & $10^{0}$ & 0,51 & & 0,56 & \\
\hline 14. Varej.:minimerc. & 0,34 & $4^{0}$ & 0,64 & & 0,49 & $5^{0}$ \\
\hline 15. Varej.: padaria & $\mathbf{0 , 3 6}$ & $6^{0}$ & 0,60 & & 0,48 & $4^{\underline{0}}$ \\
\hline 16. Varej.: outros alim. & $\mathbf{0 , 3 2}$ & $3^{-0}$ & 0,64 & & $\mathbf{0 , 4 0}$ & $3^{-0}$ \\
\hline 17. Varej.: combust.. veículos & 0,48 & $12^{0}$ & 0,48 & $8^{0}$ & 0,59 & \\
\hline 18. Varej.: fer., mat. const. & 0,45 & $10^{0}$ & 0,51 & & 0,59 & \\
\hline 19. Varej.: eletrodomésticos & 0,56 & & 0,80 & & 0,71 & \\
\hline 20. Varej.: móveis, etc. & $\mathbf{0 , 4 7}$ & $\mathbf{1 1}^{\mathbf{0}}$ & 0,49 & $9^{0}$ & 0,57 & \\
\hline 21. Varej.: tecidos & 0,40 & $8^{0}$ & 0,56 & & 0,50 & \\
\hline 22. Varej.: farmacêuticos & $\mathbf{0 , 4 1}$ & $9^{0}$ & 0,55 & & 0,55 & \\
\hline 23. Varej.: art. de vestuário & $\mathbf{0 , 3 9}$ & $7^{0}$ & 0,57 & & 0,53 & \\
\hline 24. Varej.: calçados & $\mathbf{0 , 3 5}$ & $5^{0}$ & 0,62 & & 0,49 & $5^{0}$ \\
\hline 25. Varej.:outros prod. novos & $\mathbf{0 , 4 5}$ & $10^{\underline{0}}$ & 0,51 & & 0,60 & \\
\hline
\end{tabular}

Fonte: Anexo.

01. Cultivo de frutas de lavoura permanente, exceto laranja e uva; 02. Cultivo de café; 03. Cultivo de cacau; 04. Cultivo de plantas de lavoura permanente não especificada anteriormente; 05. Criação de bovinos; 06. Atividades de apoio à agricultura; 07. Produção florestal - florestas plantadas; 08. Atividades de apoio à produção florestal; 09. Fabricação de laticínios; 10. Fabricação de produtos derivados do cacau, de chocolates e confeitos; 11. Fabricação de celulose e outras pastas para a fabricação de papel; 12. Fabricação de equipamentos de informática e Fabricação de periféricos para equipamentos de informática; 13. Comércio varejista de mercadorias em geral, com predominância de produtos alimentícios - hipermercados e supermercados; 14. Comércio varejista de mercadorias em geral, com predominância de produtos alimentícios - minimercados, mercearias e armazéns; 15. Comércio varejista de produtos de padaria, laticínio, doces, balas e semelhantes; 16. Comércio varejista de produtos alimentícios em geral ou especializado em produtos alimentícios não especificados anteriormente; 17. Comércio varejista de combustíveis para veículos automotores; 18. Comércio varejista de ferragens, madeira e materiais de construção; 19. Comércio varejista especializado de eletrodomésticos e equipamentos de áudio e vídeo; 20. Comércio varejista especializado de móveis, colchoaria e artigos de iluminação; 21. Comércio varejista especializado de tecidos e artigos de cama, mesa e banho; 22. Comércio varejista de produtos farmacêuticos para uso humano e veterinário; 23. Comércio varejista de artigos do vestuário e acessórios; 24 . Comércio varejista de calçados e artigos de viagem; 25. Comércio varejista de outros produtos novos não especificados anteriormente.

\section{CULTIVO DE CACAU}

Este setor de atividade é referência para efeito de dinamismo da economia da mesorregião Sul Baiano através de sua influência em 14 setores de atividades. Com base no \begin{tabular}{llllll}
\hline REVISTA ECONOMIA POLÍTICA DO DESENVOLVIMENTO & Maceió - AL & V.2 N.4. & DEZEMBRO/2015 & P.54-75 & Página-67
\end{tabular} 
rank dos Coeficientes de Associação Geográfica (CAik) apresentado, têm-se em $1^{\underline{0}}$ lugar as atividades de fabricação de derivados do cacau com 0,13 , liderando a possibilidade da existência despillovers, o que fica claro por ser uma atividade resultante direto do cultivo de cacau. Segue de perto em $2^{\underline{0}}$ lugar, o setor de fabricação de equipamentos de informática com 0,15 , que apesar de não ter correlação direta com o cultivo de cacau, é notório que qualquer atividade de produção hoje exige atividades de apoio com a utilização de equipamentos de informática. No $3^{\underline{0}}$ até o $7^{7^{0}}$ lugar, têm-se os setores ligado as atividades de varejo que dinamiza o comércio da região, tais como: outros alimentos com 0,32, minimercados com 0,34 , calçados com 0,35 , padarias com 0,36 e artigos de vestuário com 0,39 . Um terceiro grupo envolve os rankings do $8^{\underline{0}}$ a $12^{\underline{0}}$ lugar, distribuídos com as demais atividades de varejo: tecido com 0,40, farmacêuticos com 0,41, em 10 lugar os setores de supermercado, ferramentas e material de construção, e outros produtos novos, todos com 0,45, setor de móveis com 0,47, e combustível para veículos com o,48.

Dessa forma, verifica-se que a atividade setorial de referência "Cultivo do cacau", sinaliza para a existência de um potencial despillovers associado de 14 atividades setoriais, dentre os 25 setores selecionados, correspondendo a 56\%do total. Com menor influência de associação geográfica reservam-se para os de coeficientes cima ou igual a 0,50 com $44 \%$ do total.

\section{FABRICAÇÃO DE CELULOSE E OUTRAS PASTAS PARA A FABRICAÇÃo DE PAPEL}

Esta atividade setorial de referência neste estudo registra potencial de efeitos transbordamentos que possibilita dinamizar a economia da mesorregião Sul Baiano em 9 setores de atividades. Os Coeficientes de Associação Geográfica (CAik) estão ranqueados em relação as atividades de celulose e outros insumos para fabricação de papel da seguinte forma: em $1^{0} \mathrm{e}$ ${ }^{2}$ lugarestão as respectivas atividades de apoio apara a produção florestal com 0,00 e produção florestal com 0,01, tratando-se de setores totalmente afim com o setor de atividade de referência - celulose e outras pastas de fabricação de papel; em $3^{0}$ até o $5^{0}$ lugar envolvem o cultivo do café, as atividades de apoio à agricultura, e o cultivo de frutas de lavoura permanente, exceto laranja e uva, todas reservam alguma associação geográfica por serem atividades relacionadas com a agricultura; em $6^{0}$ e $7^{\underline{0}}$ lugares, constam atividades vinculadas a atividade da pecuária como a criação de bovinos e fabricação de laticínios, que há alguma correlação com a atividade de referência; em $8^{\underline{0}}$ e $9^{\underline{0}}$ lugares, constatam-se duas atividades de varejo descoladas - Comércio varejista de combustíveis para veículos automotores e Comércio varejista especializado de móveis, colchoaria e artigos de iluminação -, não obstante qualquer setor de referência em operação rebate com maior ou menor intensidade sobre o comércio varejista de outros setores. 
Com relação a atividade de referência "Fabricação de celulose e outras pastas para a fabricação de papel", observam-se fortes potenciais de spillovers que no conjunto dos 25 setores estudados da mesorregião Sul Baiano, estão associados em 9 setores de atividades com associação geográfica menor do que 0,50 , que corresponde a $36 \%$ do total. Os demais de Coeficientes de Associação Geográfica maior ou igual a 0,50 que tem impactos do efeito transbordamento menores correspondem a $64 \%$ do total.

\section{FABRICAÇÃO DE EQUIPAMENTOS DE INFORMÁTICA E FABRICAÇÃO DE PERIFÉRICOS PARA EQUIPAMENTOS DE INFORMÁTICA}

O setor de informática e suas atividades derivadas é base para as atividades econômicas, tornando-se presente em todos os ramos setoriais da economia. Dessa forma, é um setor que contribui para a existência despillovers elevando o nível de produtividade econômica. Na amostra utilizada para análise constatou-se que 6 atividades setoriais estão mais fortemente associadas com a atividade de referência com coeficientes abaixo de 0,50 . Em $1^{\underline{0}}$ e $2^{\underline{0}}$ lugares temos Fabricação de produtos derivados do cacau, de chocolates e confeitos com 0,02 e Cultivo de cacau com 0,15, sinalizando para o fato de essas duas atividades serem as mais robustas em ermos de atividades de produção na mesorregião. As demais atividades estão situadas no comércio varejista, tendo a seguinte sequência em termos de ranking de maior potencial de efeitos de transbordamentos desta atividade de referência: nos $3^{0}$ até o $5^{0}$ lugar estão os respectivos setores de varejo referentes à Comércio varejista de produtos alimentícios em geral ou especializado em produtos alimentícios não especificados anteriormente com 0,40; Comércio varejista de produtos de padaria, laticínio, doces, balas e semelhantes com 0,48; e em $5^{0}$ lugar, ambos os setores de Comércio varejista de mercadorias em geral, com predominância de produtos alimentícios - minimercados, mercearias e armazéns com 0,49 e Comércio varejista de calçados e artigos de viagem com 0,49. É notório que apesar do setor de informática e seus periféricos se espalharem em todos dos ramos da economia, ressaltou-se no Quadro 2 apenas os de menores coeficientes de associação da amostra selecionada (menores de 0,50) da mesorregião Sul Baiano.

Os setores de atividades estudados estão associados com maior vigor ao potencial de spillovers das atividades de informática e de seus equipamentos periféricos em 6 atividades de um total de 25 , correspondendo a uma participação de $24 \%$, restando os demais setores de atividades com intensidades menores de associação geográfica que registraram valores maiores de 0,50 , correspondendo a $76 \%$ do total. 


\section{CONCLUSÃO}

$\mathrm{O}$ artigo teve o propósito de fazer uma análise exploratória na busca de identificação de potenciais de spillovers setoriais na mesorregião Sul Baiano.Efetuou-se os cálculos dos Coeficientes de Associação Geográfica de uma amostra de atividades setoriais, tendo como referência três setores produtivos importantes na região, quais sejam: "Cultivo de cacau", "Fabricação de celulose e outras pastas para a fabricação de papel”, "Fabricação de equipamentos de informática e Fabricação de periféricos para equipamentos de informática". Depois da análise de cada um desses setores, observou-se que eles têm suas relevâncias para a economia mesorregional. Dado que se trata de uma análise pontual, digase apenas para o ano de 2013, enfatizam-se para o seu caráter de diagnósticos em seus resultados de forma exploratória, caracterizando-se as suas devidas limitações quanto ao alcance dos seus resultados e de suas deduções analíticas.

Os indicadores de associação geográfica revelaram que a atividades de referências cacau, celulose e informática - estão associados com diversos outros setores com níveis de intensidades diferentes. A atividade cacaueira e a de celulose têm as mesmas bases de produção no sentido de ser oriundo da agricultura, diferindo-se destas atividades o setor de informática que pertence ao mundo da indústria e da inovação tecnológica.

Respondendo aos três questionamentos feitos na introdução através da análise dos Coeficientes de Associação Geográfica de cada atividade setorial da amostra, fez-se as avaliações das relações dos coeficientes entre os setores de referências e destes com os demais setores de atividades da mesorregião Sul Baiano, o que propiciou fazer as seguintes deduções sobre as questões do artigo.

A primeira questão, tratando-se das relações entre as atividades de referencias verificou-se através dos indicadores de associação geográfica que o setor de "Cultivo de cacau", mostra significativa associação com a atividade de "Fabricação de equipamentos de informática e Fabricação de periféricos para equipamentos de informática". Apesar de ser respectivamente de origem setorial distinta - agricultura e indústria -, este resultado era esperado em face do setor de informática ser uma base de apoio imprescindível para a alta na produtividade de qualquer atividade econômica. Além disso, pelo fato da atividade cacaueira ter tido uma disseminação relevante no comércio e na economia da região, fortalecendo as atividades de varejos através de equipamentos e periféricos de informática.

Quanto a não associação da atividade cacaueira com o setor de celulose, pode-se encontrar uma explicação no fato das duas atividades agrícolas serem bastante diferenciadas. $\mathrm{O}$ cultivo do cacau requer um meio ambiente de matas e terras férteis e úmidas que viabilize o seu êxito, enquanto que o cultivo da silvicultura do eucalipto para a produção de celulose é

REVISTA ECONOMIA POLÍTICA DO DESENVOLVIMENTO $\quad$ Maceió - AL $\quad$ V.2 N.4. $\quad$ DEZEMBRO/2015 P.54-75 Página-70


resistente a solos degradados pelos desmatamentos do extremo sul da Bahia, não gerando impedimentos para o reflorestamento da região a base de eucaliptos. Dessa forma, trata-se de duas atividades bem distintas quanto às relações técnicas de suas agriculturas.

Um das possíveis explicações da não associação da celulose com a informática deve-se ao fato do setor da celulose, apesar de fazer uso de equipamentos de informáticas especialmente em suas atividades de apoio; este setor se caracteriza por baixa cadeia de valor, pautando-se pela produção e transporte no atacado, não se prestado com relevância a proliferação de outras atividades correlatas que propicie a disseminação no varejo de usos da informática.

Dado que a segunda questão aborda a capacidade dessas atividades de referência gerar spillovers para outros setores, constatou-se que há sim potencialidades destas atividades, tendo em vista as suas correspondentes histórias e papéis na economia em geral e especialmente na economia da mesorregião.

O "Cultivo de cacau", como é descrito no artigo é uma atividade que tem a sua história de êxitos na economia da mesorregião Sul Baiano e do estado da Bahia. Apesar da crise da segunda metade da década de 1980 provocada pela praga conhecida como "vassoura-de-bruxa", constata-se que, através do uso de uma técnica de clonagem no cultivo de um tipo de cacau geneticamente modificado, que esta atividade passou a resistir aos ataques dessa praga, fazendo com que a mesorregião voltasse a sua atividade produtiva. Observa-se que ainda é um importante setor de atividade da economia da mesorregião do Sul Baiano. Como constatado, esta atividade de referência propicia um potencial de spillovers de $56 \%$ de maior intensidade quanto ao total da amostra selecionada neste estudo, restando os $44 \%$ com potencial de menor intensidade.

A "Fabricação de celulose e outras pastas para a fabricação de papel" tem tido êxito no dinamismo econômico da mesorregião, tendo reflexo na alta populacional e no emprego com rebatimento na criação de outras atividades setoriais correlatas, a exemplo de fabricação e uso de utensílios a base de madeira, usos de papeis e afins em escritórios, rodovias para escoamento de produtos, etc. Verificou-se que dos efeitos de transbordamentos em todos os setores de atividades avaliados, apenas $36 \%$ foi enquadrado como o de maior intensidade e os outros de menores influências corresponderam a $64 \%$.

A "Fabricação de equipamentos de informática e Fabricação de periféricos para equipamentos de informática" implantada na mesorregião, mais especificamente no município de Ilhéus nos anos de 1990; foi prenunciado por alguns com certo exagero ao fazer uma analogia como promessa de um novo "Vale do Silício" em solo baiano, constatando-se ledo engano para o excesso de otimismo de alguns, tornando-se sua essência um polo de atividade 
de hards através de maquiladoras de montagem de computadores de periféricos. Este setor de atividade de referência tendo como base de sustentação os incentivos fiscais e baixo custo com mão de obra, não teve os efeitos esperados em razão de sua natureza como maquiladoras não proporcionar linkages em nível regional. Dessa forma, explica-se o seu baixo potencial de spillovers detectado na amostra estudada, que correspondeu a uma participação de alta associação geográfica de $24 \%$, enquanto que os $76 \%$ registraram baixa influência desse setor de referência para os demais setores de atividades.

Com relação à terceira questão que indaga se há significativas diferenças de potenciais de spillovers entre os três setores de atividades de referência, verificou-se que a atividades de "Cultivo do cacau" é a que de fato ainda permanece como setor de maior influência. Este resultado reflete a influência de uma atividade que historicamente tem sido presente na região e, até a primeira metade do século $\mathrm{XX}$ foi referência para a economia baiana com as alavancagens na produção e comércio da região em estudo, bem como em relação as exportações de cacau, com suas quotas sendo valoradas na bolsa de valores de New York. Os resultados da análise da amostra de 25 setores de atividades da mesorregião Sul Baiano, mostraram que em 14 setores de atividades, 56\% tiveram Coeficientes de Associação Geográfica mais próxima de zero, significando a possibilidade de fortes potenciais de spillovers do "cultivo do cacau", reservando o restante de $44 \%$ com teor baixo de associação geográfica e setorial.

As duas outras atividades de referência estudadas - "Fabricação de celulose e outras pastas para a fabricação de papel", e "Fabricação de equipamentos de informática e Fabricação de periféricos para equipamentos de informática" -, acusaram fracos potenciais de spillovers. $\mathrm{O}$ setor de celulose e de informática computou, respectivamente, com apenas 9 atividades $36 \%$ e 6 atividades $24 \%$ do total dos setores selecionadas para análises com forte associação geográfica, ficando dessa forma com potencial de spillovers abaixo de $50 \%$ da amostra.

Diante das considerações elencadas com base na aplicação e análise dos resultados do indicador de associação geográfica e setorial, o artigo se coloca como um estudo que busca fazer alguns diagnósticos do papel dos setores de atividades - "Cultivo de cacau", "Fabricação de celulose e outras pastas para a fabricação de papel" e "Fabricação de equipamentos de informática e Fabricação de periféricos para equipamentos de informática" - em promover algum efeito transbordamento através da afinidade quanto a associação geográfica em relação aos demais da mesorregião Sul Baiano. 


\section{REFERÊNCIAS}

BENCO, Georges. Indústria de alta tecnologia e desenvolvimento regional: a lógica da localização. In: Economia espaço e globalização: na aurora do século XXI. São Paulo: Ed. Hucitec, 1999.

BIANCHI, A. M. Albert Hirschman na América Latina e sua trilogia sobre desenvolvimento econômico. Economia e Sociedade, vol. 16, n. 2, Campinas, ago., 2007.

FERREIRA JÚNIOR, H.; Santos, L. D. Sistemas e arranjos produtivos locais: o caso do polo de informática de Ilhéus. Revista de Economia Contemporânea. Rio de Janeiro, 10(2): 411-442, mai./ago.. 2006.

FONSECA, Marcos. W. Hierarquização econômica dos municípios: pólos, sub-pólos e liderança setorial. In Mesorregião oeste do Paraná: diagnóstico e perspectivas, Relatório Final - Capítulo 6, Cascavel, 2002.

HADDAD, Paulo R. Padrões regionais do crescimento do emprego industrial de 1950 a 1970. Revista Brasileira de Geografia, Rio de Janeiro, 39(1) : 3-45, jan./mar. 1977

HIRSCHMAN, A. Desenvolvimento por efeitos cadeia: uma abordagem generalizada. In: SORJ, B. et. al. Economia e movimentos sociais na América Latina. São Paulo: Brasiliense. 1985.

NASCIMENTO, D. M. C.; DOMINGUEZ, J. M. L.; SILVA, S. B. M. Mudanças na ocupação econômica do litoral sul da Bahia: os exemplos de Belmonte e Canavieiras, Bahia. Revista Desenbahia, n 10, mar., 2009.

NETO, S. P. G. C. Três décadas de eucalipto no extremo sul da Bahia. GEOUSP - Espaço e Tempo, São Paulo, n³1, p. 55 - 68, 2012.

PORTER, Michael E. A vantagem competitiva das nações. Rio de Janeiro: Ed. Campos, 1989.

PORTER, M. E. Clusters and the new economics of competition. Harvard Business Review, nov./dez., 1998.

SANT'ANNA, A. G.Cluster Madeireiro: o eucalipto, a celulose e o desenvolvimento do Extremo Sul da Bahia. Revista Econômica do Nordeste, vol. 40, nº 4, out./dez., 2009.

SYRQUIN, M. Linkages and the strategy of development. In: TEITEL (org), Towards a new development strategy for Latin America - pathways from Hirschman'a thought. Washington: InterAmerican Development Bank, 1992.

TSCHÁ, O. C. P.; TOMASETTO, M. Z. C.; SHIKIDA, P. F. A.; ALVES, L. R.; BUENO, R. Encadeamento produtivo, localização e associação geográfica da agroindústria canavieira no Paraná. REDES - Revista do Desenvolvimento Regional, Santa Cruz do Sul, v. 15, n. 1, p. 128 - 155, jan./abr., 2010.

WANDERLEY, Lívio A.Produtividade da indústria alagoana no nordeste e indutores de crescimento setorial das microrregióes do estado de Alagoas: 2000 e 2013. Projeto de Pesquisa. Salvador, PPGE/UFBA, 2015. 


\begin{tabular}{|c|c|c|c|c|c|c|c|c|c|c|c|c|c|c|c|c|c|c|c|c|c|c|c|c|c|}
\hline \multirow[b]{3}{*}{ CNAE 2.0 Classe } & \multicolumn{25}{|c|}{ ANEXO - Matriz de Coeficientes de Associação Geográfica: ((SOMA j (I (Lij / Lit)*100 - (Ltj / Ltt)*100 I))/2)/100 } \\
\hline & \multicolumn{25}{|c|}{ CNAE 2.0 Classe } \\
\hline & 1 & 2 & 3 & 4 & 5 & 6 & 7 & 8 & 9 & 10 & 11 & 12 & 13 & 14 & 15 & 16 & 17 & 18 & 19 & 20 & 21 & 22 & 23 & 24 & 25 \\
\hline 1. Frutas... & 0,00 & 0,13 & 0,72 & 0,58 & 0,13 & 0,07 & 0,23 & 0,24 & 0,27 & 0,81 & 0,24 & 0,83 & 0,27 & 0,40 & 0,36 & 0,43 & 0,24 & 0,27 & 0,56 & 0,27 & 0,34 & 0,31 & 0,33 & 0,38 & 0,27 \\
\hline 2. Café & 0,13 & 0,00 & 0,85 & 0,71 & 0,19 & 0,07 & 0,10 & 0,11 & 0,33 & 0,87 & 0,11 & 0,89 & 0,40 & 0,53 & 0,49 & 0,53 & 0,36 & 0,40 & 0,69 & 0,38 & 0,45 & 0,44 & 0,46 & 0,51 & 0,40 \\
\hline 3. Cacau & 0,72 & 0,85 & 0,00 & 0,68 & 0,65 & 0,79 & 0,95 & 0,96 & 0,52 & 0,13 & 0,96 & 0,15 & 0,45 & 0,34 & 0,36 & 0,32 & 0,48 & 0,45 & 0,56 & 0,47 & 0,40 & 0,41 & 0,39 & 0,35 & 0,45 \\
\hline 4. Plantas perm... & 0,58 & 0,71 & 0,68 & 0,00 & 0,64 & 0,65 & 0,81 & 0,82 & 0,65 & 0,81 & 0,82 & 0,83 & 0,58 & 0,52 & 0,57 & 0,61 & 0,58 & 0,55 & 0,14 & 0,59 & 0,59 & 0,55 & 0,55 & 0,53 & 0,55 \\
\hline 5. Bovinos & 0,13 & 0,19 & 0,65 & 0,64 & $\mathbf{0 , 0 0}$ & 0,20 & 0,29 & 0,31 & 0,14 & 0,68 & 0,31 & 0,70 & 0,21 & 0,34 & 0,29 & 0,33 & 0,17 & 0,20 & 0,50 & 0,18 & 0,25 & 0,24 & 0,26 & 0,31 & 0,20 \\
\hline $\begin{array}{l}\text { 6. Ap.: } \\
\text { agricultura }\end{array}$ & 0,07 & 0,07 & 0,79 & 0,65 & 0,20 & 0,00 & 0,16 & 0,17 & 0,34 & 0,88 & 0,17 & 0,90 & 0,34 & 0,47 & 0,43 & 0,50 & 0,31 & 0,34 & 0,63 & 0,33 & 0,40 & 0,38 & 0,40 & 0,45 & 0,34 \\
\hline $\begin{array}{l}\text { 7. Produção } \\
\text { florestal }\end{array}$ & 0,23 & 0,10 & 0,95 & 0,81 & 0,29 & 0,16 & $\mathbf{0 , 0 0}$ & $\mathbf{0 , 0 1}$ & 0,43 & 0,97 & 0,01 & 0,99 & 0,50 & 0,63 & 0,59 & 0,63 & 0,46 & 0,50 & 0,79 & 0,48 & 0,55 & 0,54 & 0,56 & 0,61 & 0,50 \\
\hline $\begin{array}{l}\text { 8. Ap.: prod. } \\
\text { Florestal }\end{array}$ & 0,24 & 0,11 & 0,96 & 0,82 & 0,31 & 0,17 & 0,01 & $\mathbf{0 , 0 0}$ & 0,44 & 0,98 & 0,00 & 1,00 & 0,51 & 0,64 & 0,60 & 0,64 & 0,48 & 0,51 & 0,80 & 0,49 & 0,56 & 0,55 & 0,57 & 0,62 & 0,51 \\
\hline 9. Fab.: laticínios & 0,27 & 0,33 & 0,52 & 0,65 & 0,14 & 0,34 & 0,43 & 0,44 & 0,00 & 0,54 & 0,44 & 0,56 & 0,07 & 0,20 & 0,16 & 0,20 & 0,07 & 0,10 & 0,51 & 0,05 & 0,12 & 0,11 & 0,13 & 0,18 & 0,10 \\
\hline $\begin{array}{l}\text { 10. Fab. der.: } \\
\text { cacau... }\end{array}$ & 0,81 & 0,87 & 0,13 & 0,81 & 0,68 & 0,88 & 0,97 & 0,98 & 0,54 & $\mathbf{0 , 0 0}$ & 0,98 & 0,02 & 0,54 & 0,47 & 0,46 & 0,38 & 0,57 & 0,57 & 0,69 & 0,55 & 0,47 & 0,53 & 0,51 & 0,47 & 0,58 \\
\hline $\begin{array}{l}\text { 11. Fab.: celulose } \\
\text { etc. }\end{array}$ & 0,24 & 0,11 & 0,96 & 0,82 & 0,31 & 0,17 & 0,01 & 0,00 & 0,44 & 0,98 & $\mathbf{0 , 0 0}$ & 1,00 & 0,51 & 0,64 & 0,60 & 0,64 & 0,48 & 0,51 & 0,80 & 0,49 & 0,56 & 0,55 & 0,57 & 0,62 & 0,51 \\
\hline $\begin{array}{l}\text { 12. Fab. de eq. } \\
\text { infor. }\end{array}$ & 0,83 & 0,89 & 0,15 & 0,83 & 0,70 & 0,90 & 0,99 & 1,00 & 0,56 & 0,02 & 1,00 & $\mathbf{0 , 0 0}$ & 0,56 & 0,49 & 0,48 & 0,40 & 0,59 & 0,59 & 0,71 & 0,57 & 0,50 & 0,55 & 0,53 & 0,49 & 0,60 \\
\hline $\begin{array}{l}13 . \\
\text { Varej.:supermerc. }\end{array}$ & 0,27 & 0,40 & 0,45 & 0,58 & 0,21 & 0,34 & 0,50 & 0,51 & 0,07 & 0,54 & 0,51 & 0,56 & $\mathbf{0 , 0 0}$ & 0,13 & 0,09 & 0,16 & 0,04 & 0,03 & 0,44 & 0,02 & 0,07 & 0,04 & 0,06 & 0,11 & 0,04 \\
\hline $\begin{array}{l}14 . \\
\text { Varej.:minimerc. }\end{array}$ & 0,40 & 0,53 & 0,34 & 0,52 & 0,34 & 0,47 & 0,63 & 0,64 & 0,20 & 0,47 & 0,64 & 0,49 & 0,13 & $\mathbf{0 , 0 0}$ & 0,05 & 0,09 & 0,17 & 0,13 & 0,38 & 0,15 & 0,08 & 0,09 & 0,07 & 0,02 & 0,13 \\
\hline $\begin{array}{l}\text { 15. Varej.: } \\
\text { padaria }\end{array}$ & 0,36 & 0,49 & 0,36 & 0,57 & 0,29 & 0,43 & 0,59 & 0,60 & 0,16 & 0,46 & 0,60 & 0,48 & 0,09 & 0,05 & $\mathbf{0 , 0 0}$ & 0,07 & 0,12 & 0,12 & 0,43 & 0,11 & 0,04 & 0,07 & 0,05 & 0,04 & 0,12 \\
\hline $\begin{array}{l}\text { 16. Varej.: outros } \\
\text { alim. }\end{array}$ & 0,43 & 0,53 & 0,32 & 0,61 & 0,33 & 0,50 & 0,63 & 0,64 & 0,20 & 0,38 & 0,64 & 0,40 & 0,16 & 0,09 & 0,07 & 0,00 & 0,19 & 0,19 & 0,47 & 0,17 & 0,09 & 0,15 & 0,13 & 0,09 & 0,20 \\
\hline $\begin{array}{l}\text { 17. Varej.: comb. } \\
\text { Veículos }\end{array}$ & 0,24 & 0,36 & 0,48 & 0,58 & 0,17 & 0,31 & 0,46 & 0,48 & 0,07 & 0,57 & 0,48 & 0,59 & 0,04 & 0,17 & 0,12 & 0,19 & $\mathbf{0 , 0 0}$ & 0,04 & 0,44 & 0,02 & 0,10 & 0,07 & 0,09 & 0,14 & 0,04 \\
\hline $\begin{array}{l}\text { 18. Varej.: fer., } \\
\text { mat. const. }\end{array}$ & 0,27 & 0,40 & 0,45 & 0,55 & 0,20 & 0,34 & 0,50 & 0,51 & 0,10 & 0,57 & 0,51 & 0,59 & 0,03 & 0,13 & 0,12 & 0,19 & 0,04 & $\mathbf{0 , 0 0}$ & 0,41 & 0,05 & 0,10 & 0,05 & 0,06 & 0,11 & 0,00 \\
\hline $\begin{array}{l}\text { 19. Varej.: } \\
\text { eletrodomésticos }\end{array}$ & 0,56 & 0,69 & 0,56 & 0,14 & 0,50 & 0,63 & 0,79 & 0,80 & 0,51 & 0,69 & 0,80 & 0,71 & 0,44 & 0,38 & 0,43 & 0,47 & 0,44 & 0,41 & $\mathbf{0 , 0 0}$ & 0,45 & 0,45 & 0,41 & 0,41 & 0,39 & 0,41 \\
\hline $\begin{array}{l}\text { 20. Varej.:móveis, } \\
\text { etc. }\end{array}$ & 0,27 & 0,38 & 0,47 & 0,59 & 0,18 & 0,33 & 0,48 & 0,49 & 0,05 & 0,55 & 0,49 & 0,57 & 0,02 & 0,15 & 0,11 & 0,17 & 0,02 & 0,05 & 0,45 & $\mathbf{0 , 0 0}$ & 0,07 & 0,06 & 0,08 & 0,13 & 0,05 \\
\hline
\end{tabular}




\begin{tabular}{|c|c|c|c|c|c|c|c|c|c|c|c|c|c|c|c|c|c|c|c|c|c|c|c|c|c|}
\hline 21. Varej.: tecidos & 0,34 & 0,45 & 0,40 & 0,59 & 0,25 & 0,40 & 0,55 & 0,56 & 0,12 & 0,47 & 0,56 & 0,50 & 0,07 & 0,08 & 0,04 & 0,09 & 0,10 & 0,10 & 0,45 & 0,07 & 0,00 & 0,05 & 0,04 & 0,06 & 0,10 \\
\hline $\begin{array}{l}\text { 22. Varej.: } \\
\text { farmacêuticos }\end{array}$ & 0,31 & 0,44 & 0,41 & 0,55 & 0,24 & 0,38 & 0,54 & 0,55 & 0,11 & 0,53 & 0,55 & 0,55 & 0,04 & 0,09 & 0,07 & 0,15 & 0,07 & 0,05 & 0,41 & 0,06 & 0,05 & 0,00 & 0,02 & 0,07 & 0,05 \\
\hline $\begin{array}{l}\text { 23. Varej.: art. de } \\
\text { vestuário }\end{array}$ & 0,33 & 0,46 & 0,39 & 0,55 & 0,26 & 0,40 & 0,56 & 0,57 & 0,13 & 0,51 & 0,57 & 0,53 & 0,06 & 0,07 & 0,05 & 0,13 & 0,09 & 0,06 & 0,41 & 0,08 & 0,04 & 0,02 & $\mathbf{0 , 0 0}$ & 0,05 & 0,07 \\
\hline $\begin{array}{l}\text { 24. Varej.: } \\
\text { calçados }\end{array}$ & 0,38 & 0,51 & 0,35 & 0,53 & 0,31 & 0,45 & 0,61 & 0,62 & 0,18 & 0,47 & 0,62 & 0,49 & 0,11 & 0,02 & 0,04 & 0,09 & 0,14 & 0,11 & 0,39 & 0,13 & 0,06 & 0,07 & 0,05 & $\mathbf{0 , 0 0}$ & 0,11 \\
\hline $\begin{array}{l}\text { 25. Varej.:outros } \\
\text { prod. novos }\end{array}$ & 0,27 & 0,40 & 0,45 & 0,55 & 0,20 & 0,34 & 0,50 & 0,51 & 0,10 & 0,58 & 0,51 & 0,60 & 0,04 & 0,13 & 0,12 & 0,20 & 0,04 & 0,00 & 0,41 & 0,05 & 0,10 & 0,05 & 0,07 & 0,11 & $\mathbf{0 , 0 0}$ \\
\hline
\end{tabular}

Fonte: RAIS/TEM.

01. Cultivo de frutas de lavoura permanente, exceto laranja e uva; 02. Cultivo de café; 03. Cultivo de cacau; 04. Cultivo de plantas de lavoura permanente não especificadas anteriormente; 05. Criação de bovinos; 06. Atividades de apoio à agricultura; 07. Produção florestal - florestas plantadas; 08. Atividades de apoio à produção florestal; 09. Fabricação de laticínios; 10. Fabricação de produtos derivados do cacau, de chocolates e confeitos; 11. Fabricação de celulose e outras pastas para a fabricação de papel; 12. Fabricação de equipamentos de informática e Fabricação de periféricos para equipamentos de informática; 13. Comércio varejista de mercadorias em geral, com predominância de produtos alimentícios - hipermercados e supermercados; 14. Comércio varejista de mercadorias em geral, com predominância de produtos alimentícios - minimercados, mercearias e armazéns; 15. Comércio varejista de produtos de padaria, laticínio, doces, balas e semelhantes; 16. Comércio varejista de produtos alimentícios em geral ou especializado em produtos alimentícios não especificados anteriormente; 17. Comércio varejista de combustíveis para veículos automotores; 18. Comércio varejista de ferragens, madeira e materiais de construção; 19. Comércio varejista especializado de eletrodomésticos e equipamentos de áudio e vídeo; 20. Comércio varejista especializado de móveis, colchoaria e artigos de iluminação; 21. Comércio varejista especializado de tecidos e artigos de cama, mesa e banho; 22. Comércio varejista de produtos farmacêuticos para uso humano e veterinário; 23. Comércio varejista de artigos do vestuário e acessórios; 24. Comércio varejista de calçados e artigos de viagem; 25. Comércio varejista de outros produtos novos não especificados anteriormente. 